\title{
Energy poverty, shack fires and childhood burns
}

D K Kimemia, $\mathrm{PhD}$; A van Niekerk, $\mathrm{PhD}$

South African Medical Research Council-University of South Africa's Violence, Injury and Peace Research Unit, Cape Town; and Institute for Social and Health Sciences, University of South Africa, Johannesburg, South Africa

Corresponding author: D K Kimemia (david.kimemia@mrc.ac.za)

Burn injuries are a persisting challenge in South Africa. Energy poverty, prevalent in under-resourced communities, is a key contributor to the problem. The energy-poor rely on solid fuels and flammable hydrocarbons, such as paraffin, for energy services. The fuels are burnt in inefficient, leaky and unstable appliances, leading to health losses from pollutant emissions, burns, and conflagrations. Within cramped informal home settings, using flammable fuels and risky combustion technologies, the situation can become devastating, especially for young children. Those who survive fiery incidents have to contend with trauma and property losses that may lead to further impoverishment. Proactive intervention strategies are required and should include the broadening of access to safe and sustainable energy. We advocate greater enforcement of home appliance standards and targeted support for the distribution of proven alternative energy technologies, such as liquefied petroleum gas and solar power. Support and advocacy from professional and citizen groups would be necessary to ensure that government prioritises the safe energy requirements of poor citizens.

S Afr Med J 2017;107(4):289-291. DOI:10.7196/SAMJ.2017.v107i4.12436

\section{Deepening of energy poverty in South Africa}

Energy poverty, i.e. the lack of access to modern energy, is a key driver of burn injury in South Africa (SA). Energy poverty is prevalent in dense low-income settlements in developing countries, including SA. ${ }^{[1-4]}$ The dirty fuels that the energy-poor depend on are burnt in inefficient and risky combustion devices, leading to health losses - from pollutant emissions to burn injuries. ${ }^{[5,6]}$ Globally, about 2.7 billion people lack clean and safe cooking facilities and 1.2 billion have no access to electricity. ${ }^{[7]}$ The majority - $95 \%$ of these people reside either in sub-Saharan Africa or developing Asia. Household air pollution leads to the deaths of $\sim 4$ million people every year, while burns cause $\sim 265000$ deaths, including $\sim 100000$ children. ${ }^{[8]}$ A key intervention for reducing energy poverty and its consequences is the promotion of access to clean and safe energy technologies for domestic use. The access to modern energy is a prerequisite for human wellbeing, with the human development index, a measure of wellbeing, shown to increase monotonically with extra units of modern energy accessed. ${ }^{[9]}$

Various definitions of energy poverty are used by different organisations involved in this sector. The SA Department of Energy profiles energy poverty among SA households using three approaches: $(i)$ the energy poverty ratio that categorises an energy-poor household as one that 'spends more than $10 \%$ of their net income on energy procurement'; (ii) a subjective approach (based on household experiences and difficulty with the costs of their basic energy requirements); and (iii) an approach based on the thermal comfort levels of households relative to social needs, i.e. the physical state of dwellings that contribute to thermal efficiency. ${ }^{[3]}$

The expenditure-based definition classified $47 \%$ of the SA population as experiencing energy poverty in 2012, while the subjective measure cited a figure of $42 \%$ and a thermal efficiency measure of $22 \% \cdot{ }^{[3]}$ The United Nations defines energy poverty as an inability to cook with modern cooking fuels and the lack of a bare minimum of electric lighting to read or for other household and productive activities after sunset. ${ }^{\prime}{ }^{[1]}$ The Asian Development Bank has a somewhat richer definition of energy poverty and regards it as the absence of sufficient choice in accessing adequate, affordable, reliable, highquality, safe and environmentally benign energy services to support economic and human development. ${ }^{\text {'[1] }}$

\section{Shack fires and child burn injuries}

The impact of informal settlement shack fires on individuals and communities has received significant attention, with nearly 5000 informal settlement fires reported between 2009 and 2012. ${ }^{[12]}$ The effect of such fires typically results in significant economic losses and a reduced quality of life for the affected community, and often the loss of lives. Fires kill thousands of people every year, with many more disabled or seriously injured, resulting in untold and often lifelong misery and entrenched poverty. ${ }^{[13]}$ These deaths are mainly categorised as owing to flame burns, although in informal settlements liquid and food burns are also a significant cause of burn injury and hospitalisation. In SA, children are a vulnerable population, because of their more limited risk appraisal capacities and physiology. Burns may leave disabling scars to the skin or body of the child, and may also inflict notable psychological, educational and social impairment. The consequent physical and psychological adjustments may be worsened by the circumstances, severity and site(s) of the injury, the child's personality, and the access to supportive social relationships. ${ }^{[14]}$ The highest childhood burn mortality and hospitalisation rates are reported in the first 3 years of a child's life, with rates thereafter decreasing until adolescence, when burn mortality rates again start to increase. ${ }^{[15]}$ The highest concentrations of burn injury are reported in informal settlements or low-cost-housing neighbourhoods. ${ }^{[16]}$

Informal settlements are particularly vulnerable to communitywide conflagrations owing to the density of such areas, the composition of home structures and flammable building materials, the storage and use of paraffin or kerosene, the use of portable stoves and homemade bottle lamps, the overcrowded conditions in many such dwellings, and the lack of water or a restricted water supply. ${ }^{[16]}$ In such settings, the proximity of flammable material to heating sources is enhanced, with many low-income families using paraffin as their 


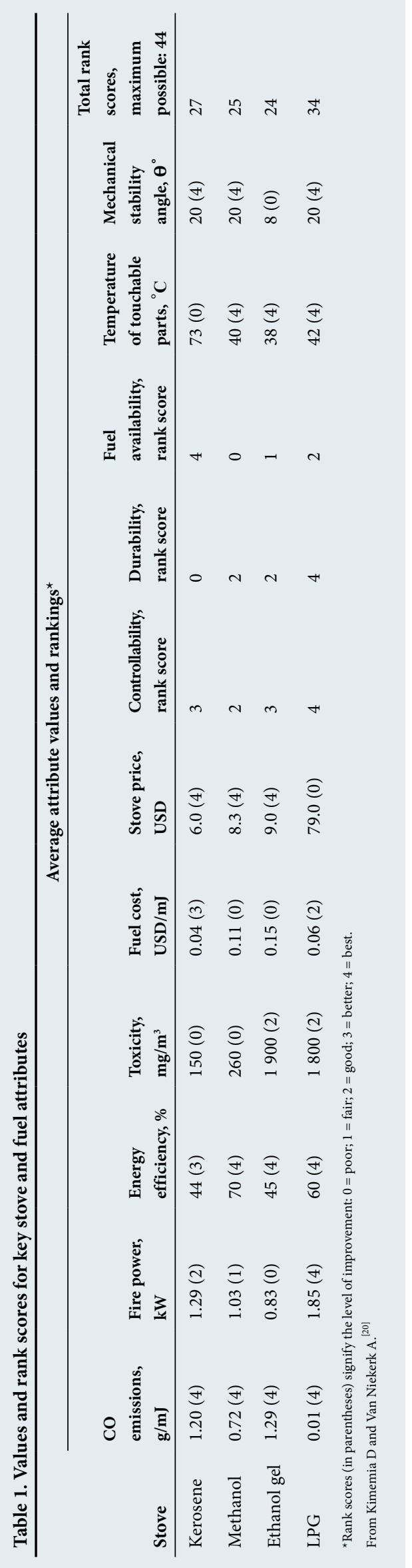

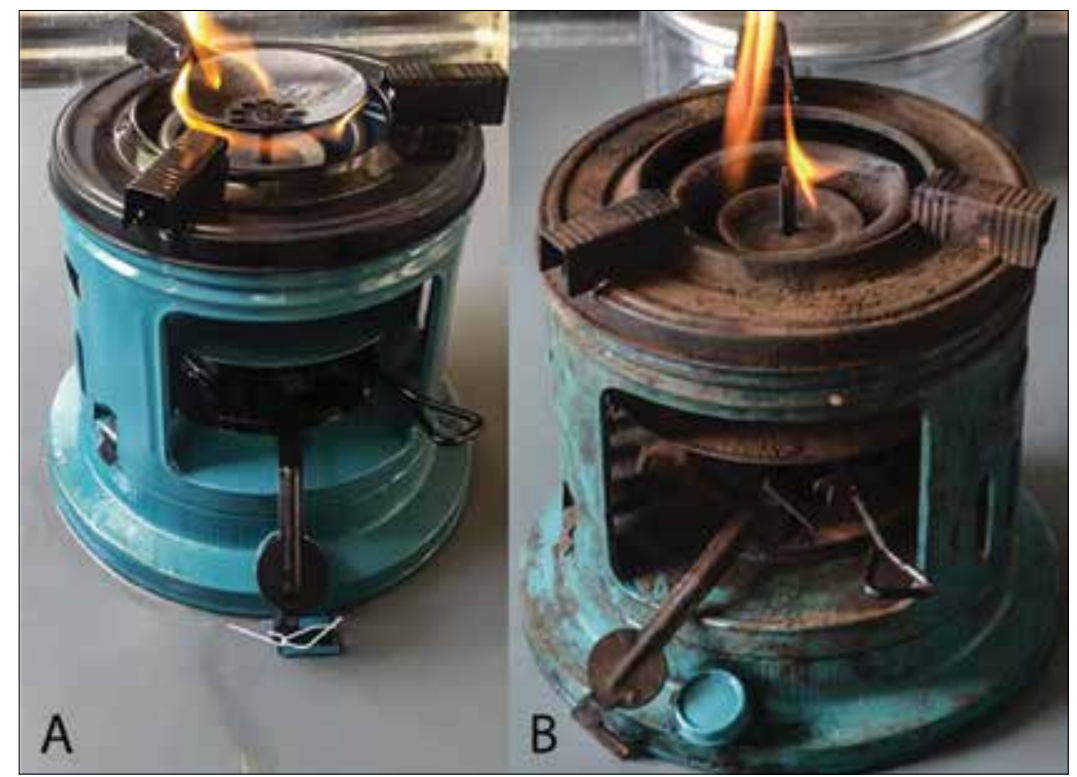

Fig 1. (A) New paraffin stove - note the fuel leak. (B) In-use stove, with a damaged self-extinguishing mechanism and flame snuffer.

main fuel source owing to its lower cost and ease of accessibility. ${ }^{[17]}$ The use of unsafe energy sources and the unsafe handling of these appliances may cause a fire or burn injury. These dangerous practices include, for example, the lighting of matches before turning on an appliance, or leaving pot handles to face outward on the stove while in use.

While paraffin stoves, wood, and candles have been implicated in most flame burn injuries, electricity is associated with the bulk of liquid and food burns. Therefore, even clean energy sources must be accompanied by safe conversion technology and awareness education on its safe uses and the emergency responses. However, despite the prioritisation of electrification in SA, it is anticipated that low-income families will continue to rely on paraffin stoves for cooking and heating tasks, because of the cost of both electricity and safe essential electrical appliances. ${ }^{[18]}$

\section{Paraffin appliances failures: Towards alternative energy}

The most hazardous of common energy appliances in use in SA is the nonpressure paraffin stove, which is also the main cause of fires and burn injuries. The SA Bureau of Standards (SABS) in 2006 enacted a national standard for non-pressure paraffin stoves and heaters (SANS1906:2012 Ed 3.1), which was subsequently declared a compulsory specification. ${ }^{[19]}$ The compulsory specification notice declares that the homologation granted in respect of an appliance type pursuant to the Specification may be withdrawn if the requirements in the Specification have not been maintained. ${ }^{[19]}$ Since then, a few wick-type paraffin stoves have been approved for manufacturing and distribution in SA. However, although these stoves may carry the SABS mark of approval, designating them as safe for domestic use, their design is reported as wanting in terms of stability, fuel leaks, flame control and general quality. ${ }^{[20]}$ Despite these concerns, such stoves continue to be manufactured and distributed with an SABS stamp.

A key requirement of SANS1906:2012 Ed 3.1 is for approved stove designs to have a self-extinguishing mechanism, which ensures that the flame is extinguished if the appliance is tilted beyond the stability limit. Although the culprit stove designs do have such a mechanism in place, it is prone to malfunction and failure within a few days to weeks of use. The reservoir tank for approved stoves is meant to be leak proof; however, recent characterisations of in-use stoves show that leaks are commonplace, even in a new, outof-the-box stove (Fig. 1). ${ }^{[20]}$ The requirement to have a steady, non-stuttering flame and sturdy construction is equally not adhered to, as shown in recent laboratory tests. These shortcomings added to overall poor construction, and short durability makes these types of stove a 'time bomb. ${ }^{[21]}$ With regard to safety, the energy-poor are exposed to harm on a continuing basis despite the paraffin stove standard and a national statutory regulator.

The technology for energy services that can provide cooked food, comfortable indoor 
temperatures and illumination in a clean, safe, and cost-effective manner does exist. The two most practical and scalable alternatives are liquefied petroleum gas (LPG) for cooking and heating, and solar power for off-grid lighting. Regarding cooking needs, a recent analysis highlights that LPG is currently the most feasible and practical clean and safe cooking technology among improved cook stove alternatives in SA (Table 1). Because of the inherent advantages, LPG has been promoted successfully as a replacement for paraffin and biomass in Senegal, India, and Indonesia. ${ }^{[22-24]}$ LPG has been piloted in selected SA communities with some success; however, there have been cost barriers, and efforts at upscaling have not been forthcoming. A dedicated policy for LPG diffusion requires serious consideration and support, with the required budgets and prioritised timelines.

\section{Conclusions and recommendations}

There is a discernible and disconcerting relationship between energy poverty and burn injury trauma. Without improving poor people's access to safe and sustainable energy, burn injuries will remain a challenge in SA. Various efforts could be activated to address energy impoverishment. Government is required to prioritise and enable modern energy access within its broader poverty eradication commitments in poor communities. However, all concerned citizens could play an active role in catalysing such a transition by demanding this greater policy focus and the required funding support for safe community energisation. We therefore urge the national and provincial governments to enact the required legislation to support the expansion of safe, healthy and efficient energy alternatives, in particular LPG and solar coverage. The relatively higher acquisition and running costs for the suggested alternatives could be overcome by means of targeted social safety nets, such as issuing a free LPG kit (stove, heater and filled cylinder) and recurring monthly subsidies on gas refills. Neighbourhoods with a high reliance on paraffin should be prioritised, with clear indications of the requisite budgets, implementation targets, and roll-out timelines. We furthermore propose that the use of paraffin as a household fuel should concurrently be actively discouraged and eventually phased out. The multiple environmental risks that relate to dwellings in makeshift, unserviced settlements, however, require a broader strategy that enables the upgrading of infrastructural arrangements and service delivery to informal settle- ments, including the reduction of housing density and provision of materials for better energy-efficient dwellings.

1. Kaygusuz K. Energy services and energy poverty for sustainable development. Renew Sustain Energ Rev 2011:15(2):936-937. https://doi.org/10.1016/j.rser.2010.11.003

2. Nussbaumer P, Brazilian M, Modi V. Measuring energy poverty: Focusing on what matters. Renew Sustain Energ Rev 2012;16(1):231-243. https://doi.org/10.1016/j.rser.2011.07.150

3. Department of Energy (South Africa). A Survey of Energy-related Behaviour and Perceptions in South Africa: The Residential Sector. Pretoria: Department of Energy, 2012.

4. Sustainable Energy Africa. Tackling Urban Energy Poverty in South Africa. Cape Town: SEA, 2014.

5. Kimemia D, Vermaak C, Pachauri S, Rhodes B. Burns, scalds and poisonings from household energy use in South Africa: Are the energy poor at greater risk? Energ Sustain Dev 2014;18(1):1-8. https://doi. org/10.1016/j.esd.2013.11.011

6. Schwebel DC, Swart D, Hui S, et al. Paraffin-related injury in low-income South African communities: Knowledge, practice and perceived risk. Bull World Health Organ 2009;87(9):700-706. https://doi.org/10.2471/ BLT.08.057505

7. International Energy Agency. Role of Sustainable Energy in Ending Poverty. Paris: IEA, 2017. http://iea. org/topics/energypoverty/ (accessed 20 February 2017).

8. World Health Organization. Household Air Pollution and Burns: Key Facts. Geneva: WHO, 2016. http:// who.int/mediacentre/factsheets/fs292/en/ (accessed 21 February 2017).

9. Goldemberg J, Johansson T, Reddy A, Williams R. A global cooking fuel initiative. Energ Sustain Dev 2004;8(3):5-12. https://doi.org/10.1016/S0973-0826(08)60462-7

0. Modi V, McDade S, Lallement D, Saghir J. Energy and the Millennium Development Goals. New York United Nations Development Programme, 2006:9.

11. Sumiya B. Energy poverty in context of climate change: What are the possible impacts of improved modern energy access on adaptation capacity of communities? Int J Environ Sci Develop 2016;7(1):73modern energy access on adaptation capacity of

12. Fire Protection Association of Southern Africa. SA National Fire Statistics 2014. Johannesburg: FPASA, 2014:40. http://fpasa.co.za/journals/sa-national-fire-statistics (accessed 6 March 2017)

13. Matzopoulos R, Prinsloo M, Pillay-van Wyk V, Gwebushe N, Mathews M, Martin LJ. Injury-related mortality in South Africa: A retrospective descriptive study of post-mortem investigations. Bull World Health Organ 2015;93(5):303-313. https://doi.org/10.2471/BLT.14.145771

14. Bakker A, Maertens KJP, van Son MJM, van Loey NEE. Psychological consequences of pediatric burns from a child and family perspective: A review of the empirical literature. Clin Psychol Rev 2013;33(3):361371. https://doi.org/10.1016/j.cpr.2012.12.006

15. Van Niekerk A, Laubscher R, Laflamme L. Demographic and circumstantial accounts of fatal burn injuries in Cape Town. A register based cross-sectional study. BMC Public Health 2009;9:374. https:// injuries in Cape Town. A register

16. Van Niekerk A, Reimers A, Laflamme L. Area characteristics and determinants of childhood burn injury in Cape Town. Public Health 2006;120(2):115-124. https://doi.org/10.1016/j.puhe.2005.08.015

17. Gevaart-Durkin A, Swart D, Chowdhury Z. A study of energy-related injuries from hospital admissions among children and adults in South Africa. Burns 2014;40(6):1209-1218. https://doi.org/10.1016/j burns.2013.12.014

18. Sustainable Energy Africa. State of energy report for Cape Town. 2003. http://sustainable.org.za/SEED (accessed 6 March 2017).

19. Department of Trade and Industry, South Africa. Compulsory specification for non-pressure kerosene stoves and heaters. Government Gazette No. 29338:1091. 2006

20. Kimemia D, van Niekerk A. Cookstove options for safety and health: Comparative analysis of technological and usability attributes. Energ Pol 2017;(epub ahead of print). https://doi.org/10.1016/j.
to enpol.2017.03.022

21. Abahlali baseMjondolo. Warning on 'time bomb' paraffin stoves. 2007. http://abahlali.org/node/2821/ (accessed 27 February 2017).

22. Andadari R, Mulder P, Rietveld P. Energy poverty reduction by fuel switching: Impact evaluation of the LPG conversion program in Indonesia. Ener Pol 2014;66(1):436-449. https://doi.org/10.1016/j. enpol.2013.11.021

23. Budya $\mathrm{H}$, Arofat M. Providing cleaner energy access in Indonesia through the megaproject of kerosene conversion to LPG. Ener Pol 2011;39(12):7575-7586. https://doi.org/10.1016/j.enpol.2011.02.061

24. Natarajan M. Differences between intentional and non-intentional burns in India: Implications for prevention. Burns 2014;40(5):1033-1039. https://doi.org/10.1016/j.burns.2013.12.002 